\title{
Ratio Scale
}

National Cancer Institute

\section{Source}

National Cancer Institute. Ratio Scale. NCI Thesaurus. Code C47800.

A scale that uses ordered numbers with a constant difference and which has a natural zero. 